\title{
miR-218 on the genomic loss region of chromosome 4p15.31 functions as a tumor suppressor in bladder cancer
}

\author{
SHUICHI TATARANO ${ }^{1}$, TAKESHI CHIYOMARU ${ }^{1}$, KAZUMORI KAWAKAMI $^{1}$, HIDEKI ENOKIDA ${ }^{1}$, \\ HIROFUMI YOSHINO ${ }^{1}$, HIDEO HIDAKA ${ }^{1}$, TAKESHI YAMASAKI ${ }^{1}$, KAZUYA KAWAHARA ${ }^{2}$, \\ KENRYU NISHIYAMA ${ }^{1}$, NAOHIKO SEKI $^{3}$ and MASAYUKI NAKAGAWA ${ }^{1}$ \\ ${ }^{1}$ Department of Urology, Graduate School of Medical and Dental Sciences, Kagoshima University; \\ ${ }^{2}$ Kawahara Nephro-urology Clinic, Kagoshima; ${ }^{3}$ Department of Functional Genomics, \\ Graduate School of Medicine, Chiba University, Chiba, Japan
}

Received January 21, 2011; Accepted March 18, 2011

DOI: 10.3892/ijo.2011.1012

\begin{abstract}
Growing evidence suggests that microRNAs (miRNAs) are aberrantly expressed in many human cancers, and that they play significant roles in carcinogenesis and cancer progression. The identification of tumor suppressive miRNAs and their target genes could provide new insights into the mechanism of carcinogenesis. However, the genetic or epigenetic regulations of these miRNAs have not yet been fully elucidated in bladder cancer (BC). Chromosomal alterations of cancer cells give us important information for the identification of tumor suppressor genes. Our miRNA arraycomparative genomic hybridization $(\mathrm{CGH})$ analysis showed several miRNAs to be candidate tumor suppressors of BC. Our array-CGH analysis revealed that chromosome 4 was lost in all BC cell lines. We selected 19 miRNAs located on chromosome 4 and evaluated their expression levels in cancer cell lines as well as clinical samples. Gain-of-function analysis revealed that miR-218 inhibited $\mathrm{BC}$ cell proliferation, migration and invasion. Furthermore, flow cytometry analysis showed that it induced BC cell apoptosis. Genome-wide gene expression analysis showed that it targeted multiple oncogenes in BC. Our study is the first to demonstrate that $m i R-218$ located on chrosomosme $4 \mathrm{p} 15.31$ is a tumor suppressive miRNA in BC. The identification of tumor suppressive miRNAs and their target genes on the basis of array-CGH analysis could provide new insights into the mechanisms of $\mathrm{BC}$ carcinogenesis.
\end{abstract}

Correspondence to: Dr Hideki Enokida, Department of Urology, Graduate School of Medical and Dental Sciences, Kagoshima University, 8-35-1 Sakuragaoka, Kagoshima 890-8520, Japan E-mail: enokida@m.kufm.kagoshima-u.ac.jp

Key words: microRNA, $m i R-218$, array-comparative genomic hybridization, $4 \mathrm{p} 15.31$, bladder cancer

\section{Introduction}

Bladder cancer (BC) is the fourth most common cancer in Western industrialized countries and the second most common cancer of the genitourinary tract. In Japan, the age-standardized mortality rate of $\mathrm{BC}$ has remained relatively stable in men but has increased slightly since 1993 in women (1). There have been significant advances in treatment, including surgical techniques and adjuvant chemotherapy. However, BC continues to be a common disease with high mortality (2). To date, the mechanisms of BC carcinogenesis have not been fully investigated. Hence, new treatment modalities based on novel molecular targets in $\mathrm{BC}$ are desired.

MicroRNAs (miRNAs) are an abundant class of small non-coding RNAs, about 22 nucleotides in length, and they function as negative regulators (cleavage or translational repression) of gene expression by antisense complimentary to specific mRNAs. Although their biological functions remain largely unknown, recent studies have suggested that alterations in miRNA expression contribute to the development of various malignancies. To date, a spectrum of cancer-associated miRNAs has been identified, and some miRNAs function as tumor suppressors and other miRNAs act as oncogenes, inducing or promoting cancer development or progression. We previously determined the miRNA expression signatures specific to BC (3) and reported that several down-regulated miRNAs function as tumor suppressors and that their target genes have typical oncogenic functions (4-6).

Aberrant miRNA expressions in cancers are caused by single nucleotide polymorphism, mutations in pri-miRNA sequences, alterations in the copy number of miRNA coding regions, and so forth (7). Genomic alterations often account for down-regulated miRNA expression in malignancies. For example, the down-regulated miRNAs, the miR-15/miR-16 cluster and $m i R-213$, are located at 13q14 and chromosome 1; these are genomic loss regions in chronic B cell lymphoma and ovarian cancer $(8,9)$. However, the up-regulated miRNAs, let-7a-3 and the miR-9-1 cluster, are respectively found in the genomic gain region of chromosome 22 and 1 in ovarian cancer (9), and the miR-17-92 cluster is located at the gain 
region of $13 q 31.3$ in lung cancer (10). These candidate miRNAs were selected according to the genomic loss and gain regions where they were harbored on the basis of comparative genomic hybridization (CGH) analyses, leading to an important strategy for indentifying tumor-associated miRNAs. However, the genetic or epigenetic regulations of these miRNAs have not yet been fully elucidated in BC. Microarray-based CGH has been used in a number of studies to study copy number instability and aberration type in BC samples. Ours and other studies have shown that frequent copy number gains occur at chromosome 1, 3, 5, 6, 8, 10, 11, $12,17,19$ and 20, while copy number losses occur at chromosome 2, 4, 5, 8, 9, 10, 11, 13 and 18 in $\mathrm{BC}(11-15)$. We focused on chromosome 4 because almost the whole genomic region of choromosome 4 was detected as lost loci in all BC cell lines, and miRNAs on this chromosome were the most numerous of the lost loci examined in our previous study (16). We therefore hypothesized that the chromosomal loss region harbors down-regulated miRNAs that have a tumor suppressive function through the negative regulation of oncogenes in $\mathrm{BC}$. To test this hypothesis, we measured the expression levels of 19 miRNAs located on chromosome 4 in clinical BC samples and BC cell lines. We performed a cell viability assay and apoptosis assay on $\mathrm{BC}$ cell lines transfected with candidate miRNAs. Furthermore, we performed an oligo-microarray analysis to identify genes regulated by the candidate miRNAs.

\section{Materials and methods}

$B C$ cell lines and cell culture. We used four human BC cell lines. T24 and UMUC were obtained from the American Type Culture Collection. KK47, which was established at Kanazawa University from an Asian male patient aged 50 years with a diagnosis of stage I BC, was kindly provided to us by colleagues there, and BOY was established in our laboratory from an Asian male patient aged 66 years diagnosed with stage III BC with lung metastasis (17). These cell lines were maintained in a minimum essential medium (MEM) supplemented with $10 \%$ fetal bovine serum in a humidified atmosphere of $5 \% \mathrm{CO}_{2}$ and $95 \%$ air at $37^{\circ} \mathrm{C}$.

Tissue samples. Tissue samples were taken from $16 \mathrm{BC}$ patients who had undergone cystectomy or transurethral resection of $\mathrm{BCs}$ and six normal bladder epithelium (NBE) samples were derived from organ-confined prostate cancer patients who underwent prostatectomy at Kagoshima University Hospital between 2006 and 2009 (Table I). Another series of $28 \mathrm{BCs}$ and 10 NBEs was subjected to real-time RT-PCR for evaluating mRNA expression levels of the target gene in more clinical samples (Table II). The samples were staged in accordance with the tumor-nodemetastasis classification system of the American Joint Committee on Cancer/Union Internationale Contre le Cancer (UICC) and were histologically graded (18). Also studied were six NBE samples derived from organ-confined prostate cancer patients who underwent prostatectomy. The study was approved by the Bioethics Committee of Kagoshima University. Written informed consent and approval were given by the patients prior to the study.
Table I. Patient characteristics.

\begin{tabular}{|c|c|}
\hline \multicolumn{2}{|l|}{ Bladder cancer (BC) } \\
\hline Total number & 16 \\
\hline Median age (range) in years & $75(55-88)$ \\
\hline \multicolumn{2}{|l|}{ Gender } \\
\hline Male & 11 \\
\hline Female & 5 \\
\hline \multicolumn{2}{|l|}{ Stage } \\
\hline $\mathrm{pTa}$ & 5 \\
\hline pT1 & 4 \\
\hline pT2 & 2 \\
\hline pT3 & 1 \\
\hline pT4 & 2 \\
\hline Unknown & 2 \\
\hline \multicolumn{2}{|l|}{ Grade } \\
\hline G1 & 0 \\
\hline G2 & 9 \\
\hline G3 & 7 \\
\hline \multicolumn{2}{|l|}{ Operation } \\
\hline Radical cystectomy & 8 \\
\hline TUR-Bt & 8 \\
\hline \multicolumn{2}{|l|}{ Recurrence } \\
\hline Recurrence (+) & 7 \\
\hline Recurrence (-) & 8 \\
\hline Unknown & 1 \\
\hline \multicolumn{2}{|c|}{ Normal bladder epithelium (NBE) } \\
\hline Total number & 6 \\
\hline
\end{tabular}

Tissue collection and RNA extraction. Tissue samples were immersed in RNAlater (Qiagen, Valencia, CA, USA) and stored at $-20^{\circ} \mathrm{C}$ until the RNA extraction. Total RNA including miRNA was extracted from frozen fresh tissues using the mirVana $^{\mathrm{TM}}$ miRNA isolation kit (Ambion, Austin, TX, USA) in accordance with the manufacturer's instructions. The integrity of the RNA was checked with an RNA 6000 Nano Assay Kit and a 2100 Bioanalyzer $^{\mathrm{TM}}$ (Agilent Technologies, Santa Clara, CA, USA).

Quantitative real-time RT-PCR. TaqMan probes and primers for thioredoxin-related transmembrane protein 1 (TMX1) (TaqMan ${ }^{\circledR}$ Gene Expression Assays; P/N: Hs00991569_m1 for TMX1; Applied Biosystems, Foster City, CA, USA) were assay-on-demand gene expression products. All reactions were performed in duplicate, and a negative-control lacking cDNA was included. We followed the manufacturer's instructions for the PCR conditions. Stem-loop RT-PCR (TaqMan MicroRNA Assays; Applied Biosystems) was used to quantify miRNAs according to the earlier published conditions (3). cDNA was made from $5 \mathrm{ng}$ of total RNA from each sample using the TaqMan MicroRNA Reverse Transcription Kit (Applied Biosystems) and miRNA specific primers (Applied Biosystems) for 19 down-regulated (miR-95, miR-548i-2, miR-572, miR-218, miR-573, miR-574-3p, miR-1269, miR-575, miR-1255a, miR-576-5p, miR-576-3p, miR-367, miR-302d, miR-302a, miR-302c, miR-302b, miR-577, miR-548g and $m i R-578)$ miRNA species. For the quantitative analysis of mRNA and miRNA, we used human $18 s \quad r R N A(\mathrm{P} / \mathrm{N}$ : 
Table II. Patient characteristics.

\begin{tabular}{|c|c|}
\hline \multicolumn{2}{|l|}{ Bladder cancer (BC) } \\
\hline Total number & 28 \\
\hline Median age (range) in years & $73(56-91)$ \\
\hline \multicolumn{2}{|l|}{ Gender } \\
\hline Male & 19 \\
\hline Female & 9 \\
\hline \multicolumn{2}{|l|}{ Stage } \\
\hline $\mathrm{pTa}$ & 5 \\
\hline pT1 & 8 \\
\hline pT2 & 5 \\
\hline pT3 & 5 \\
\hline pT4 & 2 \\
\hline Unknown & 3 \\
\hline \multicolumn{2}{|l|}{ Grade } \\
\hline G1 & 1 \\
\hline G2 & 18 \\
\hline G3 & 6 \\
\hline Unknown & 3 \\
\hline \multicolumn{2}{|l|}{ Operation } \\
\hline Radical cystectomy & 10 \\
\hline Partial cystectomy & 1 \\
\hline TUR-Bt & 17 \\
\hline \multicolumn{2}{|l|}{ Recurrence } \\
\hline Recurrence (+) & 18 \\
\hline Recurrence (-) & 7 \\
\hline Unknown & 3 \\
\hline \multicolumn{2}{|c|}{ Normal bladder epithelium (NBE) } \\
\hline Total number & 10 \\
\hline
\end{tabular}

Hs99999901_s1; Applied Biosystems) and RNU48 (P/N: 001006; TaqMan MicroRNA Assays; Applied Biosystems) as the internal control, and we used the $\Delta \Delta \mathrm{Ct}$ method to calculate the fold-change.

Mature miRNA transfection. As described previously (3), the BC cell lines were transfected with Lipofectamine ${ }^{\mathrm{TM}}$ RNAiMAX transfection reagent (Invitrogen, Carlsbad, CA, USA) and Opti-MEM $^{\text {TM }}$ (Invitrogen) with $10 \mathrm{nM}$ of mature miRNA molecules. Pre-miR ${ }^{\mathrm{TM}}$ and negative control miRNA (Applied Biosystems) were used in the gain-of-function experiments. Cells were seeded in a $10-\mathrm{cm}$ dish for protein extraction $\left(8 \times 10^{5}\right.$ per dish), in a 6 -well plate for the apoptosis $\left(10 \times 10^{4}\right.$ per well) wound healing assays $\left(20 \times 10^{4}\right.$ per well), in a 24 -well plate for the mRNA extraction and matrigel invasion assay $\left(5 \times 10^{4}\right.$ per well), and in a 96-well plate for the 2,3-bis-(2methoxy-4-nitro-5-sulfophenyl)-2H- tetrazolium-5-carboxanilide (XTT) assay (3,000 per well).

Cell proliferation, wound healing and matrigel invasion assay. Cell proliferation was determined by using an XTT assay (Roche Applied Sciences, Tokyo, Japan) performed according to the manufacturer's instructions. Cell migration activity was evaluated by wound healing assay. Cells were plated in 6-well dishes, and the cell monolayer was scraped using a P-20 micropipette tip. The initial gap length $(0 \mathrm{~h})$ and the residual gap length $24 \mathrm{~h}$ after wounding were calculated from photomicrographs. A cell invasion assay was carried out using modified Boyden chambers consisting of transwell-precoated matrigel membrane filter inserts with $8-\mu \mathrm{m}$ pores in 24-well tissue culture plates (BD Biosciences, Bedfold, MA, USA). MEM containing 10\% fetal bovine serum in the lower chamber served as the chemoattractant, as described previously (4). All experiments were performed in triplicate.

Apoptosis analysis. BC cell lines transiently transfected with miR-control and miR-218 in 6-well tissue culture plates, as described previously, were harvested $72 \mathrm{~h}$ after transfection by trypsinization and washed in cold PBS. Double staining with FITC-Annexin V and propidium iodine (PI) was carried out using the FITC Annexin V Apoptosis Detection Kit (BD Biosciences) according to the manufacturer's recommendations and immediately analyzed within an hour by flow cytometry (FACScan ${ }^{\circledR}$; BD Biosciences). Cells were discriminated into visible cells, dead cells, early apoptotic cells and apoptotic cells using CellQuest software (BD Biosciences), and then the percentages of early apoptotic cells from each experiment were compared. Experiments were done in triplicate.

Oligonucleotide microarray analysis of BC cell lines. Oligomicroarray Human 44K (Agilent) was used for expression profiling in $m i R$-218-transfected BC cell lines (BOY and T24) in comparison to the miR-negative control transfectant, as previously described (4). Briefly, hybridization and washing steps were performed in accordance with the manufacturer's instructions. The arrays were scanned using a Packard GSI Lumonics ScanArray ${ }^{\circledR} 4000$ (Perkin-Elmer, Boston, MA, USA). The data were analyzed by means of DNASIS ${ }^{\circledR}$ array software (Hitachi Software Engineering), which converted the signal intensity for each spot into text format. The $\log ^{2}$ ratios of the median subtracted background intensity were analyzed. Data from each microarray study were normalized by global normalization.

Statistical analysis and predicting target genes of candidate miRNAs. The relationship between two variables and the numerical values obtained by real-time RT-PCR was analyzed using the Mann-Whitney $U$ test. The relationship between three variables and the numerical values was analyzed using the Bonferroni-adjusted Mann-Whitney U test. Expert StatView ${ }^{\circledR}$ analysis software (version 4, SAS Institute Inc., Cary, NC, USA) was used. In the comparison of three variables, a nonadjusted statistical level of significance of $\mathrm{P}<0.05$ corresponded to a Bonferroni-adjusted level of $\mathrm{P}<0.0167$. We used the TargetScan program (release 5.1, http://www.targetscan.org/) to identify the predicted target genes and their conserved sites for the candidate miRNAs.

\section{Results}

Selection of miRNAs located on chromosome 4 by array-CGH analysis. To produce a comprehensive survey of genomic aberrations in $\mathrm{BC}$, in our previous study we had analyzed a $\mathrm{BC}$ cell line using array-CGH for patterns of chromosomal gains and/or losses [NCBI GEO (http://www.ncbi.nlm.nih. gov/geo) under accession no. GSE19714] (16). Predominantly lost loci were observed at chromosomes $4 p$ and $4 q$ in all of the 


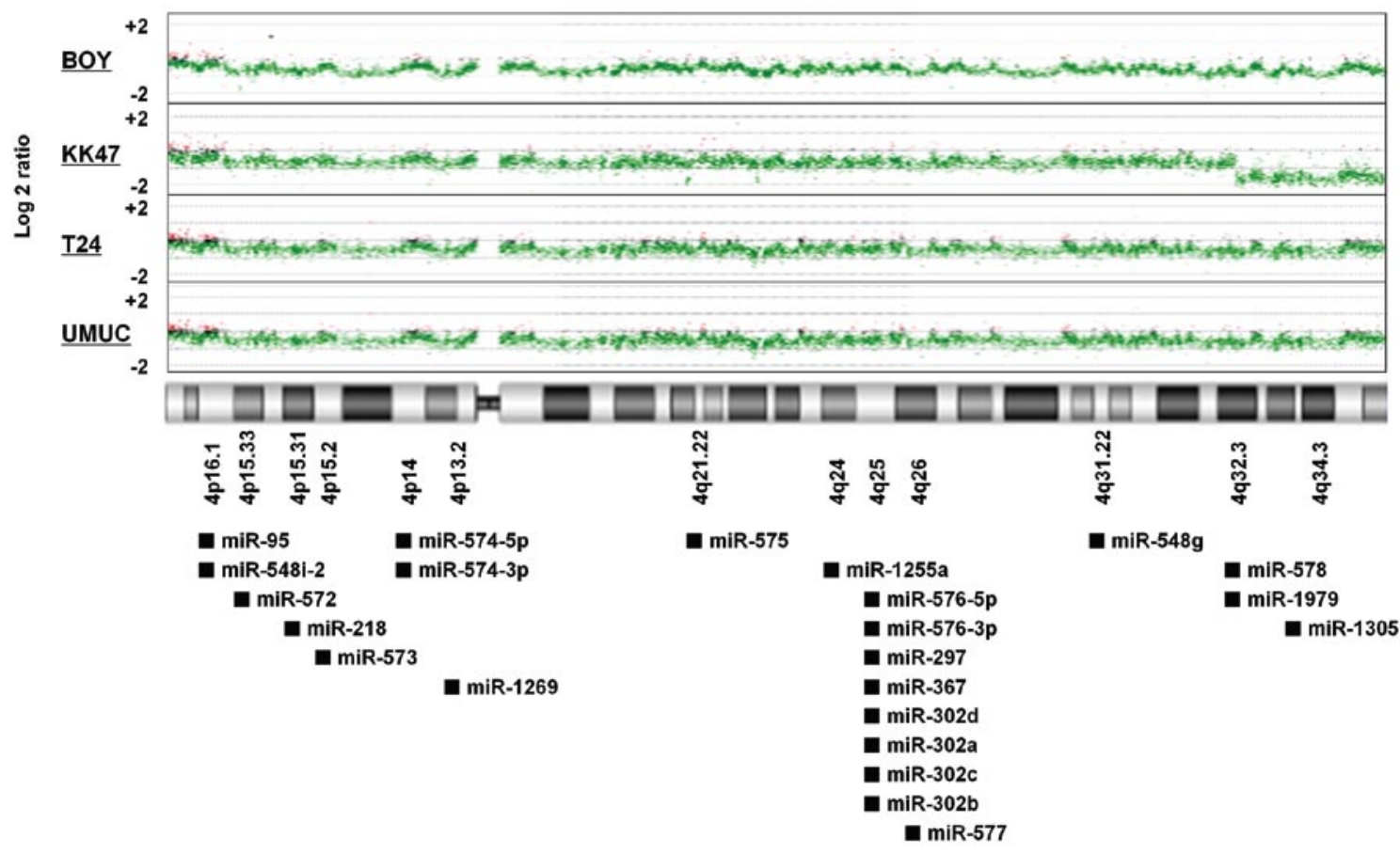

Figure 1. Array-CGH profiling of four BC cell lines showing chromosomal alterations. Integer value recurrence of copy number alterations in segmented data (y-axis) was plotted for each probe aligned along the $\mathrm{x}$-axis in chromosome order. Red and green bars denote gain and loss of chromosome material, respectively.

(A)

\begin{tabular}{|c|c|c|c|c|c|c|c|c|c|c|c|c|c|c|c|c|c|c|c|}
\hline $\begin{array}{l}\text { miRNAs/ } \\
\text { cell lines }\end{array}$ & 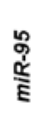 & 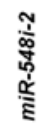 & \begin{tabular}{l} 
స్ \\
\multirow{\alpha}{\alpha}{} \\
$\underline{\underline{E}}$
\end{tabular} & 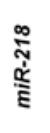 & 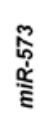 & 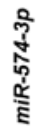 & 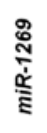 & 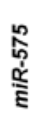 & 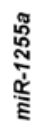 & 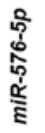 & $\begin{array}{l}\text { शे } \\
\text { ơ } \\
\text { रे } \\
\frac{\alpha}{2} \\
\text { है }\end{array}$ & 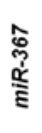 & 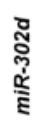 & 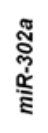 & 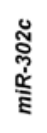 & 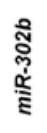 & $\begin{array}{l}\widehat{\hat{W}} \\
\stackrel{\alpha}{\alpha} \\
\underline{\underline{E}}\end{array}$ & 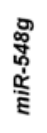 & 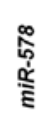 \\
\hline BOY & & & & & & & & & & & & & & & & & & & \\
\hline KK 47 & & & & & & & & & & & & & & & & & & & \\
\hline T24 & & & & & & & & & & & & & & & & & & & \\
\hline uмuc & & & & & & & & & & & & & & & & & & & \\
\hline
\end{tabular}

(B)

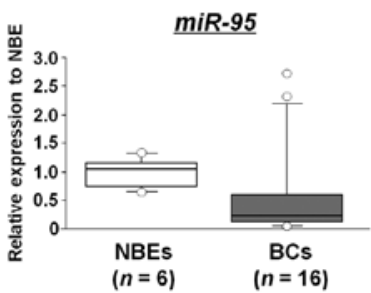

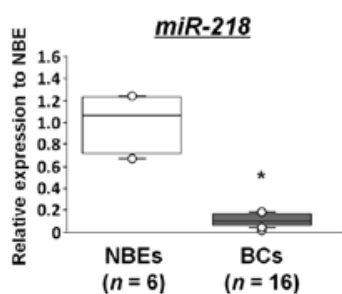

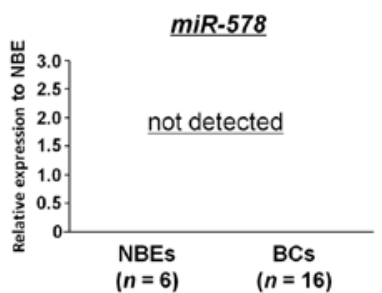

Figure 2. (A) Fold number changes for the 19 miRNAs located in genomic loss lesion of chromosome 4 in four BC cell lines in comparison to NBEs. RNU48 served as the internal control for quantitative PCR analysis, and the $\Delta \Delta \mathrm{Ct}$ method was used to calculate the fold-change. Fold-changes were classified with the following cut-off values: $<0.01$-fold (significant loss, white boxes), 0.01 to 0.05 -fold (loss, light grey boxes), 0.05 to 1 -fold (no significant change, medium grey boxes), $1-20$ fold (gain, dark grey boxes), and $\geq 20$-fold (and/or saturated bands due to significant amplification; significant gain, black boxes). (B) miRNA expression levels in clinical samples. ${ }^{*} \mathrm{P}<0.0005$.

cell lines. The miRNAs located at chromosomes $4 p$ and $4 q$ were the most numerous among the lost loci. Therefore, we focused on the 23 miRNAs located at the loci for further expression analysis (Fig. 1). Predicted mature miRNAs on the loci were checked by referring to the miRBase (release 16.0, http://microrna.sanger.ac.uk/).
Expression levels of 19 miRNAs located on chromosome 4 in $B C$ cell lines and clinical samples. We validated the results from our array-CGH data by subjecting 19 commercially available miRNAs to stem-loop RT-PCR in four BC cell lines (BOY, KK47, T24 and UMUC) and NBEs (n=6) (Fig. 2A). Four miRNAs (miR-574-5p, miR-297, miR-1979 and miR-1305) 
Table III. miRNAs located on chromosome 4.

Fold-change (relative to normal bladder)

\begin{tabular}{|c|c|c|c|c|c|c|c|c|}
\hline \multirow[b]{2}{*}{ Start } & \multirow[b]{2}{*}{ Stop } & \multirow[b]{2}{*}{ Chromosome } & \multirow{2}{*}{$\begin{array}{c}\text { Name } \\
\text { (probe/miRNA) }\end{array}$} & \\
\hline & & & & BOY & KK47 & $\mathrm{T} 24$ & UMUC & Ave. \\
\hline 4287997 & 33228242 & $4 \mathrm{p} 16.1$ & hsa-miR-95 & 0.0427613 & 0.5031809 & 0.0094856 & 0.0034675 & 0.1397238 \\
\hline 4287997 & 33228242 & $4 \mathrm{p} 16.1$ & hsa-miR-548i-2 & 1.7096628 & 0.4576802 & 0.0721034 & 0.3940667 & 0.6583783 \\
\hline 4287997 & 33228242 & $4 \mathrm{p} 15.33$ & hsa-miR-572 & 1.1977477 & 1.6125278 & 2.0549083 & 0.4495097 & 1.3286734 \\
\hline 4287997 & 33228242 & $4 \mathrm{p} 15.31$ & hsa-miR-218 & 0.0077479 & 0.0112099 & 0.0034201 & 0.001115 & 0.0058732 \\
\hline 4287997 & 33228242 & $4 p 15.2$ & hsa-miR-573 & 11.256885 & 27.410101 & 2.1250338 & 14.683111 & 13.868783 \\
\hline 33228242 & 48407013 & $4 \mathrm{p} 14$ & hsa-miR-574-5p & U.D. & U.D. & U.D. & U.D. & U.D. \\
\hline 33228242 & 48407013 & $4 \mathrm{p} 14$ & hsa-miR-574-3p & 0.0573489 & 0.0549099 & 0.0806719 & 0.0177487 & 0.0526699 \\
\hline 52395637 & 165513713 & $4 \mathrm{p} 13.2$ & hsa-miR-1269 & 1.1164664 & 0.0472609 & 0.0448558 & 0.2436851 & 0.363067 \\
\hline 52395637 & 165513713 & $4 \mathrm{q} 21.22$ & hsa-miR-575 & 0.0104471 & 0.0894827 & 0.0414539 & 0.0606206 & 0.0505011 \\
\hline 52395637 & 165513713 & $4 q 24$ & hsa-miR-1255a & 4.5455321 & 4.2749252 & 0.0763303 & 0.7569916 & 2.4134448 \\
\hline 52395637 & 165513713 & $4 q 25$ & hsa-miR-576-5p & 0.4765729 & 0.4794057 & 0.5477232 & 1.0035197 & 0.6268054 \\
\hline 52395637 & 165513713 & $4 q 25$ & hsa-miR-576-3p & 0.8984586 & 0.6162441 & 1.0221621 & 0.8076622 & 0.8361318 \\
\hline 52395637 & 165513713 & $4 q 25$ & hsa-miR-297 & U.D. & U.D. & U.D. & U.D. & U.D. \\
\hline 52395637 & 165513713 & $4 q 25$ & hsa-miR-367 & 0.0678592 & 0.0801579 & 0.1013971 & 0.2366109 & 0.1215063 \\
\hline 52395637 & 165513713 & $4 q 25$ & hsa-miR-302d & 0.0620643 & 0.1266358 & 0.1370959 & 0.1382985 & 0.1160236 \\
\hline 52395637 & 165513713 & $4 q 25$ & hsa-miR-302a & 0.0369271 & 0.0436197 & 0.1033904 & 0.1562821 & 0.0850548 \\
\hline 52395637 & 165513713 & $4 q 25$ & hsa-miR-302c & 1.1410754 & 0.2212799 & 0.2888604 & 0.2351404 & 0.471589 \\
\hline 52395637 & 165513713 & $4 q 25$ & hsa-miR-302b & 0.2963494 & 7.4040835 & 0.8279819 & 0.5162426 & 2.2611644 \\
\hline 52395637 & 165513713 & $4 q 26$ & hsa-miR-577 & 27.822078 & 32.243988 & 79.924077 & 30.224745 & 42.553722 \\
\hline 52395637 & 165513713 & $4 \mathrm{q} 31.22$ & hsa-miR-548g & 6.8904384 & 1.6620869 & 2.1024854 & 1.0046519 & 2.9149156 \\
\hline 165513713 & 166878658 & $4 q 32.3$ & hsa-miR-578 & 0.0056292 & 0.0066494 & 0.0183694 & 0.0084998 & 0.0097869 \\
\hline 165513713 & 166878658 & $4 q 32.3$ & hsa-miR-1979 & U.D. & U.D. & U.D. & U.D. & U.D. \\
\hline 182271163 & 191112750 & $4 q 34.3$ & hsa-miR-1305 & U.D. & U.D. & U.D. & U.D. & U.D. \\
\hline
\end{tabular}

Ave., average; U.D., undetermined due to no probe available.

were not commercially available at the time of this experiment (Table III). When we looked at miRNAs for which the expression was $<0.01$-fold in at least two of four BC cell lines, we found that $m i R-95, m i R-218$ and $m i R-578$ remained strongly down-regulated miRNAs on chromosome 4 in BC cell lines (Table III and Fig. 2A). To validate these miRNA expressions in clinical samples, we subjected $16 \mathrm{BCs}$ and six NBEs to stem-loop RT-PCR (Table I). We found a significant difference in $m i R-218$ expression between them $(0.111 \pm 0.014$ and $1.000 \pm 0.102$, respectively, $\mathrm{P}=0.0004$ ) (Fig. $2 \mathrm{~B}$ ), but no significant differences in miR-95 expression between BCs and NBEs, and no expression of $m i R-578$ was detected in any of the BCs or NBEs. Consequently, we chose $m i R-218$ for the gain-of-function studies. There were no significant correlations between miRNA expression and clinicopathological parameters (data not shown).

Effect of miR-218 transfection on cell proliferation, migration, invasion activity and cell apoptosis in BC cell lines. To examine the functional role of these miRNAs, we performed gain-of-function studies using the miRNA transfectants. The XTT assay showed significant cell proliferation inhibition in miR-218 transfectants compared to the controls from BOY and T24 cell lines (\% of cell proliferation; BOY, $55.4 \pm 1.6$ and
$100 \pm 4.8, \mathrm{P}<0.0001 ; \mathrm{T} 24,72.9 \pm 1.6$ and $100 \pm 1.5, \mathrm{P}<0.0001$; Fig. 3A). The wound healing assay also demonstrated significant cell migration inhibition in the $m i R-218$ transfectant compared to the counterparts (\% of wound closure; BOY, $32 \pm 5.3$ and $100 \pm 8.8, \mathrm{P}=0.0001 ; \mathrm{T} 24,51.6 \pm 9$ and $100 \pm 6$, $\mathrm{P}=0.0018$; Fig. 3B). The matrigel invasion assay demonstrated that the number of invading cells was significantly decreased in the $m i R-218$ transfectant compared to the counterparts (BOY, 105.6 \pm 9 and 238.1 $\pm 7.9, \mathrm{P}=0.0008 ; \mathrm{T} 24,109.3 \pm 3.6$ and 244.6 $\pm 13.2, \mathrm{P}=0.0008$; Fig. $3 \mathrm{C}$ ). The early apoptotic cell fractions (right lower quadrant) were greater in the $m i R-218$ transfectant than in the miR-control transfectant (early apoptotic cells relative to the control; BOY, 5.96 \pm 1.07 and 1.00 \pm 0.40 , $\mathrm{P}=0.0016$; $\mathrm{T} 24,3.63 \pm 0.35$ and $1.00 \pm 0.16, \mathrm{P}=0.0008)$ (Fig. 3D). These results suggest that $m i R-218$ expression can induce cell apoptosis in BC cells.

Gene expression profile identifying differentially expressed genes in miR-218 transfectant. To gain further insight into which genes are down-regulated by $m i R-218$ in $\mathrm{BC}$, we performed gene expression analysis of $m i R-218$ transfectants (BOY and T24) (Fig. 4). We identified 162 genes that were generally up-regulated in $m i R-218$ transfectants by $>2$-fold compared to the control transfectant. In contrast, 337 genes 
(A)

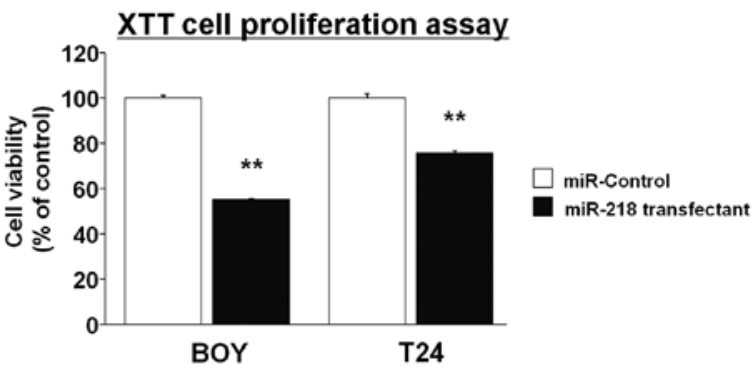

(B)

Wound healing assay

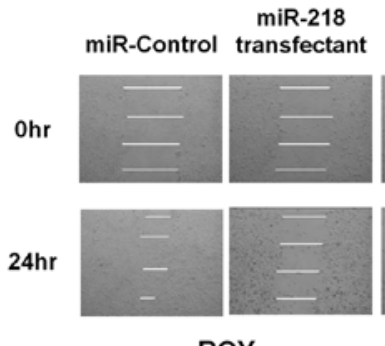

BOY
miR-218 transfectant

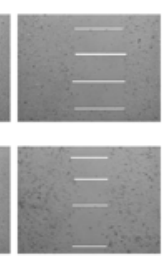

T24

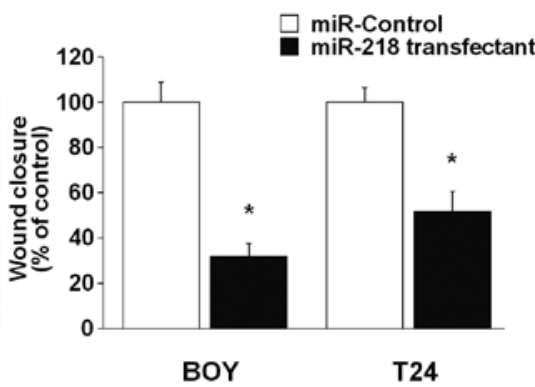

(C)

\section{Invasion assay}

BOY

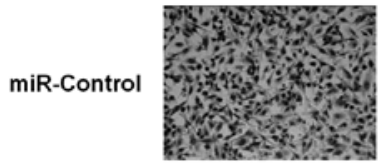

miR-218 transfectant

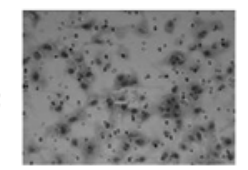

(D)

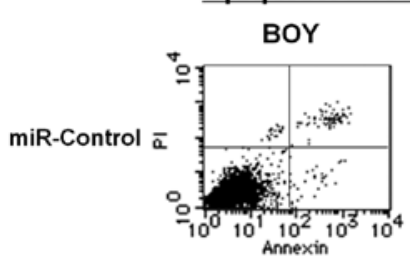

Apoptosis assay

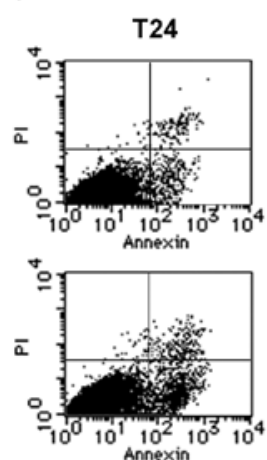

T24
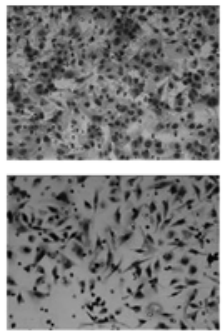

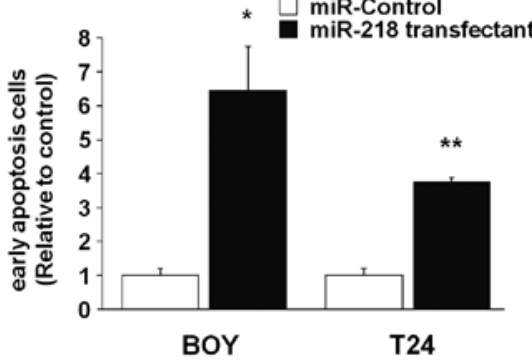

Figure 3. Gain of function studies in BC cell lines with miR-218 transfectants. (A) Cell proliferation determined by the XTT assay in BOY and T24 cell lines transfected with the miRNAs. ${ }^{* *} \mathrm{P}<0.0001$. (B) Significant cell migration inhibitions were observed in BOY and T24 cell lines transfected with $m i R-218$. Phase micrographs of BOY and T24 cell lines taken at 0 and $24 \mathrm{~h}$ after monolayer wounding are shown on the left panel. Quantification of cell migration using the monolayer wound healing assay is shown on the right panel. ${ }^{*} \mathrm{P}<0.01$. (C) Significant cell invasion inhibitions were observed in BOY and T24 cell lines transfected with miR-218. Phase micrographs of invading BOY and T24 cell lines are shown on the left panel. Quantifications of cell invasion are shown on the right panel. ${ }^{* *} \mathrm{P}<0.0001$. (D) Apoptosis assay by flow cytometry. Significant early apoptotic cells were observed in BOY and T24 cell lines transfected with $m i R-218$. Early apoptotic cells can be seen in the bottom right quadrant (D, left panel). The normalized ratio of the apoptosis assay is shown in the histogram. Percentage of early apoptotic cells out of the total measured cell population for miR-control and $m i R$ - 218 -transfected $\mathrm{BC}$ cell lines. ${ }^{*} \mathrm{P}<0.01$. ${ }^{* *} \mathrm{P}<0.0001$.

were down-regulated by $<-2$-fold in the transfectants. The functional annotations of the up- and down-regulated genes were respectively classified into 11 and 8 categories (Fig. 4). The gene expression profile of $m i R-218$ transfectants demonstrated that the up-regulated gene categories included tumor suppressive categories, such as regulation of transcription, anatomical structure development and apoptosis, whereas down-regulated gene categories included oncogenic categories, such as signal transduction, regulation of apoptosis and cell cycle. The oligonucleotide array data are available for reference 
(A)

Up-regulated genes $(n=162)$

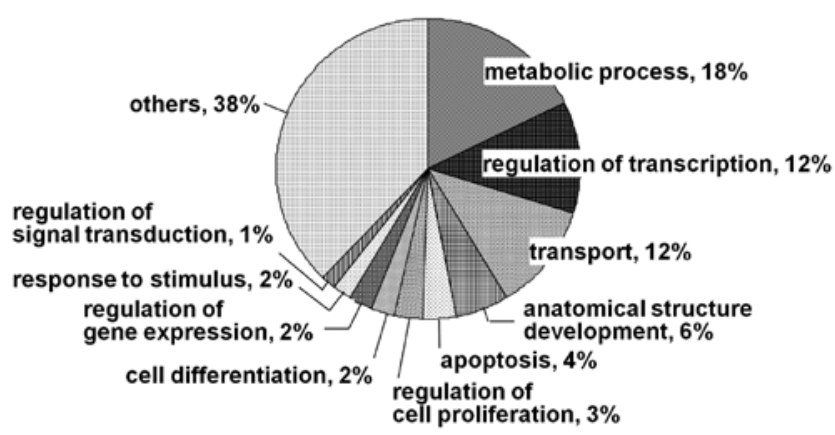

(B)

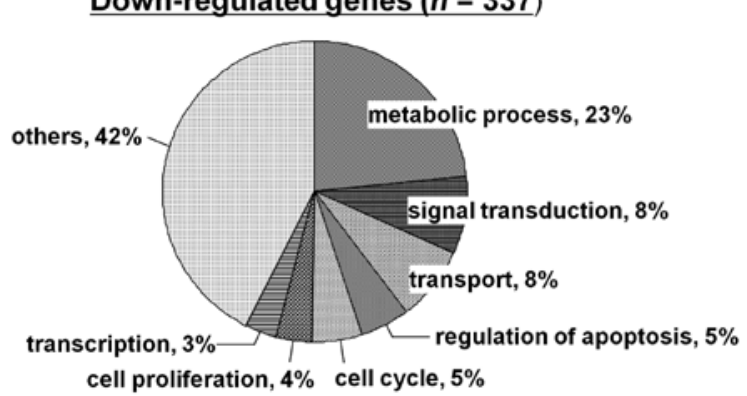

Figure 4. Distribution of altered expression of functionally categorized genes in BOY and $\mathrm{T} 24 / m i R-218$ transfectant compared to the control transfectant. The functional features of the 162 up- (A) and 337 down- (B) regulated genes. These genes were classified into 11 and 8 categories.

[NCBI GEO (http://www.ncbi.nlm.nih.gov/geo) under accession no. GSE24782].

Identification of candidate miR-218 target genes by expression profiles. On the basis of our oligo-microarray data, TMX1 was at the top of the down-regulated genes that had conserved sites for $m i R-218$. Therefore, we focused on this gene as a target of $m i R-218$. The quantitative real-time RT-PCR analysis showed that the mRNA expression levels of $T M X 1$ in the BOY and T24 cell lines were higher than in the NBEs $(n=10)$ (Fig. 5A), and the expression levels of TMX1 were markedly repressed in the $m i R-218$ transfectants in comparison to the control (Fig. 5B). Our quantitative real-time RT-PCR showed that there was a trend but no significant difference in TMX1 mRNA expression between clinical BCs and NBEs $(\mathrm{P}=0.0734)$ (Fig. 5C). There were no significant correlations between TMX1 mRNA expression and clinicopathological parameters (data not shown).

\section{Discussion}

The mechanisms underlying miRNA gene expression in cancer are not well understood. Although genomic alterations are critical in oncogenesis $(19,20)$, studies have so far focused mostly on protein-coding genes. As more than half of the miRNAs have been aligned to genomic fragile sites or regions associated with cancers, miRNA expression levels could change along with the gene copy number of where they were
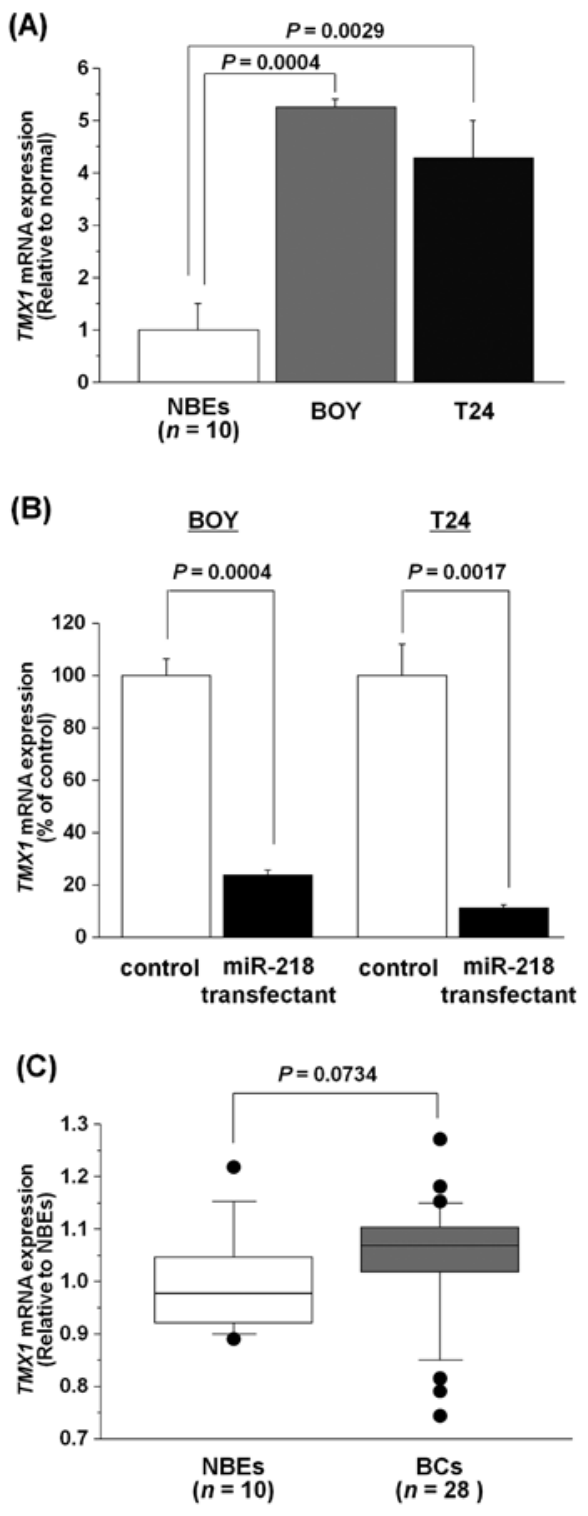

Figure 5. (A) The mRNA expression of $T M X 1$ in BOY and $T 24$ cell lines and normal human bladder RNA (BOY, $\mathrm{P}=0.0004$; T24, $\mathrm{P}=0.0015$ ). (B) $T M X 1$ mRNA expression $24 \mathrm{~h}$ after transfection with $10 \mathrm{nM}$ of $m i R-218$ (BOY, $\mathrm{P}=0.0004 ; \mathrm{T} 24, \mathrm{P}=0.0017$ ). (C) Real-time RT-PCR analysis of mRNA expression levels of TMX1 in clinical BCs and NBEs.

harbored. Calin et al showed that the $m i R-15 / m i R-16$ cluster was located at chromosome $13 \mathrm{q} 14$, a region deleted in more than half of chronic B cell lymphomas. They focused on the $m i R-15 / m i R-16$ cluster located within a $30-\mathrm{kb}$ region on the basis of CGH analysis of chronic B cell lymphoma (8). Previous studies have reported copy number losses in chromosomes $4 \mathrm{p}$ and $4 \mathrm{q}$ in clinical BC and BC cell lines (21-24). Consistent with these previous studies, our array-CGH data demonstrated that chromosome 4 was the typical chromosomal loss region and miRNAs on this chromosome were the most numerous of the lost loci, suggesting that inactivating these miRNAs on chromosome 4 could play an important role in $\mathrm{BC}$ development. A recent study identified that $m i R-218$, which is located at chromosome 4p15.31, was down-regulated according to genome-wide array-CGH data combined with a bioinformatics 
Table IV. Top 20 down-regulated genes, which have putative $m i R-218$ target sites, in $m i R-218$ transfectants.

\begin{tabular}{|c|c|c|c|}
\hline Gene ID & Gene symbol & Gene name & Fold-change \\
\hline 81542 & $T M X 1$ & Thioredoxin-related transmembrane protein 1 & 0.21 \\
\hline 81552 & VOPP1 & Vesicular, overexpressed in cancer, prosurvival protein 1 & 0.21 \\
\hline 1069 & CETN2 & Centrin, EF-hand protein, 2 & 0.22 \\
\hline 10447 & FAM3C & Family with sequence similarity 3 , member $\mathrm{C}$ & 0.24 \\
\hline 9770 & $R A S S F 2$ & Ras association (RalGDS/AF-6) domain family member 2 & 0.27 \\
\hline 2771 & GNAI2 & Guanine nucleotide binding protein (G protein), $\alpha$ inhibiting activity polypeptide 2 & 0.28 \\
\hline 91409 & $C C D C 74 B$ & Coiled-coil domain containing 74B & 0.28 \\
\hline 9801 & MRPL19 & Mitochondrial ribosomal protein L19 & 0.28 \\
\hline 131566 & $D C B L D 2$ & Discoidin, CUB and LCCL domain containing 2 & 0.31 \\
\hline 79155 & TNIP2 & TNFAIP3 interacting protein 2 & 0.31 \\
\hline 79443 & FYCOI & FYVE and coiled-coil domain containing 1 & 0.31 \\
\hline 7275 & $T U B$ & Tubby homolog (mouse) & 0.32 \\
\hline 8601 & $R G S 20$ & Regulator of G-protein signaling 20 & 0.32 \\
\hline 5500 & $P P P 1 C B$ & Protein phosphatase 1 , catalytic subunit, $\beta$ isozyme & 0.32 \\
\hline 81618 & ITM2C & Integral membrane protein $2 \mathrm{C}$ & 0.33 \\
\hline 51762 & $R A B 8 B$ & RAB8B, member RAS oncogene family & 0.33 \\
\hline 81617 & $C A B 39 L$ & Calcium binding protein 39-like & 0.34 \\
\hline 54951 & COMMD8 & COMM domain containing 8 & 0.34 \\
\hline 6091 & $\mathrm{ROBOl}$ & Roundabout, axon guidance receptor, homolog 1 (Drosophila) & 0.35 \\
\hline 6470 & SHMT1 & Serine hydroxymethyltransferase 1 (soluble) & 0.35 \\
\hline
\end{tabular}

mapping approach for lung cancer (25). Consistently, we found that the expression levels of certain miRNAs, including $m i R-218$ were down-regulated in clinical BC specimens as well as BC cell lines. Thus, miRNA profiling based on our array-CGH data is a new strategy for finding crucial miRNAs in human BC. However, there was no typical down-regulation of several miRNAs on chromosome 4 in this study. Some miRNAs, such as miR-548i-1, $-2,-3$ and -4 , are located at several chromosomal loci and have common mature miRNA sequences but are located at different chromosomes. Hence, their expression levels might not decrease unless all loci are simultaneously deactivated. In terms of $m i R-218$, there are two genes that code for mature $m i R-218$. $m i R-218-1$ is located on chromosome $4 \mathrm{p} 15.31$, and $m i R-218-2$ is located on chromosome $5 \mathrm{p} 34$. We observed a genomic loss region on chromosome 4 p15.31, but not on chromosome 5 p34 in the array-CGH of $\mathrm{BC}$ cell lines. Therefore, it is possible that the genomic loss of the $4 \mathrm{p} 15.31$ is an important reason for the down-regulation of $m i R-218$ in BC, although other mechanisms might also work to down-regulate $m i R-218$ expression derived from $m i R-218-2$. Further studies are required in order to elucidate the precise mechanisms of $m i R-218$ regulation.

Recently, a down-regulation of $m i R-218$ has been reported as tumor suppressive miRNA in several kinds of tumors, including gastric cancer $(26,27)$, lung cancer (25), cervical cancer (28), head and neck cancer (29) and prostate cancer (30). However, there have been no functional studies of $m i R-218$ in BC. Ours is the first report demonstrating that miR-218 may have a tumor suppressive function in BC. $m i R-218$ is an intronic miRNA. One gene code for mature
miR-218-1 is located within the intron 15 of slit homologue 2 (SLIT2), a tumor suppressor gene. SLIT2 has been intensively investigated, and it has been found to be frequently downregulated in lung cancers, breast cancers (31), glioma (32), cervical cancer (33) and hepatocellular carcinoma (34). However, miR-218 directly regulates roundabout 1 (ROBOI), which is known to be a receptor of SLIT2 (SLIT/ROBO pathway) by inducing apoptosis in certain human malignancies. Simultaneous inactivations of $m i R-218$ and SLIT2, which are in the same region of chromosome $4 \mathrm{p} 15$, imply that large losses in this region might be crucial for BC carcinogenesis and development. Another study demonstrated that prosurvival protein 1 (VOPPl), which activated nuclear factor $\kappa \mathrm{B}(\mathrm{NF}-\kappa \mathrm{B})$ and was associated with anti-apoptotic response, was a direct target of $m i R-218$ (26). ROBOl and VOPPl were among the top 20 down-regulated genes in our oligo-microarray data using $m i R$-218-transfected BC cell lines (Table IV), suggesting that these molecules may have tumor suppressive functions and could be directly regulated by $m i R-218$ in BC.

The gene expression profile of $m i R-218$ transfectants in this study suggests that $m i R-218$ expression can affect downregulating genes classified into oncogenic categories and up-regulating genes classified into tumor suppressive categories. The expression levels of the TMX1 gene, which was the top down-regulated gene in $m i R-218$ transfectants and was reported to have an anti-apoptotic function (35), was actually overexpressed in clinical BC samples and downregulated by $m i R-218$ transfection. These results suggest that $m i R-218$ and its target gene may be a gene therapy candidate for clinical BC. In this study, there was no significant relation- 
ship between $m i R-218$ expression and clinicopathological parameters. Our cohort was too small to evaluate the relationship between them.

In conclusion, we demonstrate that $m i R-218$ is downregulated in $\mathrm{BC}$ and that it is located in the loss locus, 4p15.31, in $\mathrm{BC}$ cell lines. We found decreased cell proliferation, migration and invasion activity, and increased cell apoptosis in $m i R-218$ transfectants, suggesting that $m i R-218$ is a candidate tumor suppressive miRNA of human BC.

\section{Acknowledgments}

This research was partially supported by the Ministry of Education, Science, Sports and Culture Grants-in-Aid for Scientific Research (B and C), 20390427 and 20591861, 2008. We thank Ms. Mutsumi Miyazaki for her excellent laboratory assistance.

\section{References}

1. Qiu D, Katanoda K, Marugame T and Sobue T: A Joinpoint regression analysis of long-term trends in cancer mortality in Japan (1958-2004). Int J Cancer Jan 124: 443-448, 2009.

2. Shirodkar SP and Lokeshwar VB: Potential new urinary markers in the early detection of bladder cancer. Curr Opin Urol 19: 488-493, 2009.

3. Ichimi T, Enokida H, Okuno Y, et al: Identification of novel microRNA targets based on microRNA signatures in bladder cancer. Int J Cancer 125: 345-352, 2009.

4. Chiyomaru T, Enokida H, Tatarano S, et al: miR-145 and miR-133a function as tumor suppressors and directly regulate FSCN1 expression in bladder cancer. Br J Cancer 102: 883-891, 2010.

5. Chiyomaru T, Enokida H, Kawakami K, et al: Functional role of LASP1 in cell viability and its regulation by microRNAs in bladder cancer. Urol Oncol: Sep 14, 2010 (Epub ahead of print).

6. Uchida Y, Chiyomaru T, Enokida H, et al: MiR-133a induces apoptosis through direct regulation of GSTP1 in bladder cancer cell lines. Urol Oncol: Mar 9, 2011 (Epub ahead of print).

7. Li M, Li J, Ding X, He M and Cheng SY: microRNA and cancer. AAPS J 12: 309-317, 2010.

8. Calin GA, Dumitru CD, Shimizu M, et al: Frequent deletions and down-regulation of microRNA genes miR15 and miR16 at $13 q 14$ in chronic lymphocytic leukemia. Proc Natl Acad Sci USA 99: 15524-15529, 2002.

9. Zhang L, Huang J, Yang N, et al: Micro-RNAs exhibit high frequency genomic alterations in human cancer. Proc Natl Acad Sci USA 103: 9136-9141, 2006.

10. Hayashita Y, Osada H, Tatematsu Y, et al: A polycistronic microRNA cluster, is overexpressed in human lung cancers and enhances cell proliferation. Cancer Res 65: 9628-9632, 2005.

11. Stoehr R, Wissmann C, Suzuki H, et al: Deletions of chromosome $8 \mathrm{p}$ and loss of sFRP1 expression are progression markers of papillary bladder cancer. Lab Invest 84: 465-478, 2004.

12. Blaveri E, Brewer JL, Roydasgupta R, et al: Tubulin: a target for antineoplastic drugs into the cancer cells but also in the peripheral nervous system. Curr Med Chem 16: 1315-1324, 2009.

13. Yamamoto Y, Chochi Y, Matsuyama H, et al: Gain of $5 \mathrm{p} 15.33$ is associated with progression of bladder cancer. Oncology 72: 132-138, 2007.

14. Shinoda Y, Kozaki K, Imoto I, et al: Association of $K L K 5$ overexpression with invasiveness of urinary bladder carcinoma cells. Cancer Sci 98: 1078-1086, 2007.

15. Hurst CD, Tomlinson DC, Williams SV, Platt FM and Knowles MA: Inactivation of the $\mathrm{Rb}$ pathway and overexpression of both isoforms of E2F3 are obligate events in bladder tumors with 6p22 amplification. Oncogene 27: 2716-2727, 2008.
16. Matsuda R, Enokida H, Chiyomaru T, et al: LY6K is a novel molecular target in bladder cancer on basis of integrate genomewide profiling. Br J Cancer 104: 376-386, 2011.

17. Takemoto M, Shirahama T, Miyauchi T, et al: Metanestin, a glycoprotein with metastasis-associated expression in transitional cell carcinoma of the urinary bladder. Int J Cancer 74: 7-14, 1997.

18. Sobin LH and Wittekind C: TNM Classification of Malignant Tumors. In: International Union Against Cancer (UICC). 6th edition. Wiley-Liss Publications, New York, pp199-202, 2002.

19. Albertson DG, Collins C, McCormick F and Gray JW: Chromosome aberrations in solid tumors. Nat Gene 34: 369-376, 2003.

20. Bentley DR: Genomics for medicine. Nature 429: 440-445, 2003.

21. Knowles MA, Elder PA, Williamson M, Cairns JP, Shaw ME and Law MG: Allelotype of human bladder cancer. Cancer Res 54: 531-538, 1994

22. Rosin MP, Cairns P, Epstein JI, Schoenberg MP and Sidransky D: Partial allelotype of carcinoma in situ of the human bladder. Cancer Res 55: 5213-5216, 1995.

23. Polascik TJ, Cairns P, Chang WY, Schoenberg MP and Sidransky D: Distinct regions of allelic loss on chromosome 4 in human primary bladder carcinoma. Cancer Res 55: 5396-5399, 1995.

24. Hurst CD, Fiegler H, Carr P, Williams S, Carter NP and Knowles MA: High-resolution analysis of genomic copy number alterations in bladder cancer by microarray-based comparative genomic hybridization. Oncogene 23: 2250-2263, 2004.

25. Davidson MR, Larsen JE, Yang IA, et al: MicroRNA-218 is deleted and downregulated in lung squamous cell carcinoma. PLoS One 5: e12560, 2010.

26. Gao C, Zhang Z, Liu W, Xiao S, Gu W and Lu H: Reduced microRNA-218 expression is associated with high nuclear factor kappa B activation in gastric cancer. Cancer 116: 41-49, 2010.

27. Tie J, Pan Y, Zhao L, et al: MiR-218 inhibits invasion and metastasis of gastric cancer by targeting the Robol receptor. PLoS Genet 6: e1000879, 2010.

28. Martinez I, Gardiner AS, Board KF, Monzon FA, Edwards RP and Khan SA: Human papillomavirus type 16 reduces the expression of microRNA-218 in cervical carcinoma cells. Oncogene 27: 2575-2582, 2008.

29. Wald AI, Hoskins EE, Wells SI, Ferris RL and Khan SA: Alteration of microRNA profiles in squamous cell carcinoma of the head and neck cell lines by human papillomavirus. Head Neck 33: 504-512, 2011

30. Leite KR, Sousa-Canavez JM, Reis ST, et al: Change in expression of miR-let7c, miR-100, and miR-218 from high grade localized prostate cancer to metastasis. Urol Oncol: April 15, 2009 (Epub ahead of print).

31. Dallol A, Da Silva NF, Viacava P, et al: SLIT2, a human homologue of the Drosophila Slit2 gene, has tumor suppressor activity and is frequently inactivated in lung and breast cancers. Cancer Res 62: 5874-5880, 2002.

32. Dallol A, Krex D, Hesson L, Eng C, Maher ER and Latif F: Frequent epigenetic inactivation of the SLIT2 gene in gliomas. Oncogene 22: 4611-4616, 2003.

33. Singh RK, Indra D, Mitra S, et al: Deletions in chromosome 4 differentially associated with the development of cervical cancer: evidence of slit 2 as a candidate tumor suppressor gene. Hum Genet 122: 71-81, 2007.

34. Jin J, You H, Yu B, et al: Epigenetic inactivation of SLIT2 in human hepatocellular carcinomas. Biochem Biophys Res Commun 379: 86-91, 2009.

35. Matsuo Y, Akiyama N, Nakamura H, Yodoi J, Noda M and Kizaka-Kondoh S: Identification of a novel thioredoxin-related transmembrane protein. J Biol Chem 276: 10032-10038, 2001. 